\title{
Networked Carbon Markets
}

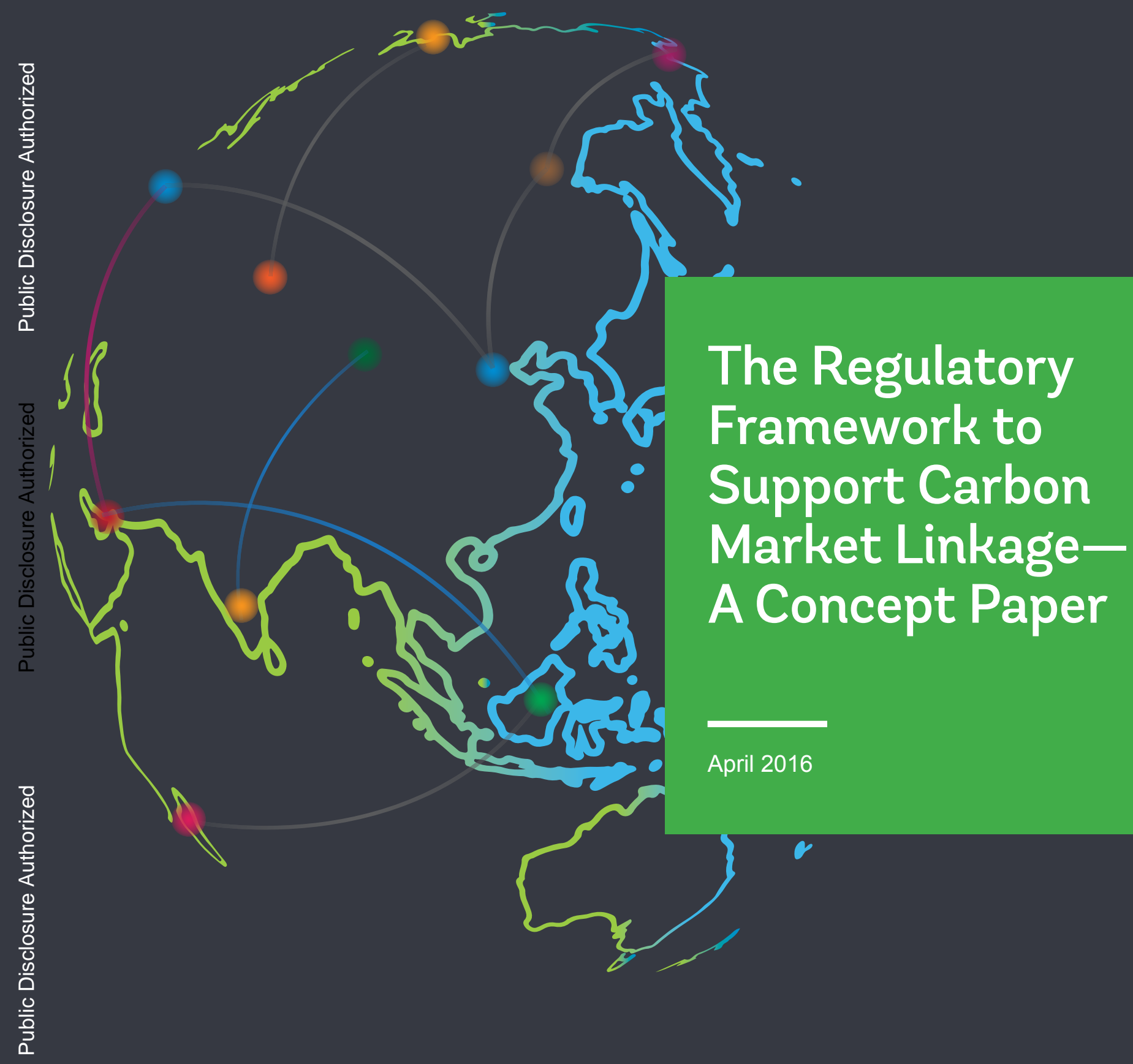


Networked Carbon Markets

\section{The Regulatory Framework to Support Carbon Market Linkage- A Concept Paper}

April 2016

Peter Zaman and Adam Hedley 


\section{Acknowledgements}

This report was prepared jointly by the World Bank and Reed Smith.

The World Bank team included Chandra Shekhar Sinha, Bianca Sylvester and Rachel Mok. The report also benefited from the guidance and valuable contributions by World Bank colleagues, Celine Ramstein and Pierre Guigon.

The Reed Smith team included Peter Zaman and Adam Hedley. Peter Zaman is a partner in Reed Smith's Singapore office and Adam Hedley is a senior associate in Reed Smith's London office.

This work is a product of the staff of The World Bank with external contributions. The findings, interpretations, and conclusions expressed in this work do not necessarily reflect the views of The World Bank, its Board of Executive Directors, or the governments they represent. The World Bank does not guarantee the accuracy of the data included in this work." 


\section{Contents}

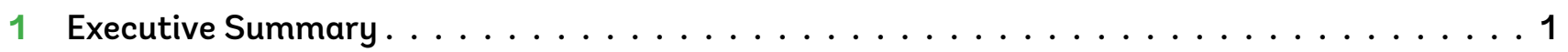

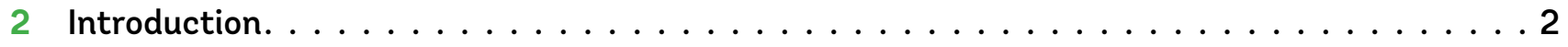

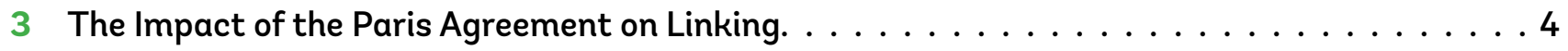

4 Governance, Legal and Regulatory Frameworks. . . . . . . . . . . . . . 6

5 The Regulatory Framework for Carbon Markets Linked under the NCM . . . . . . . . . . . . 9

6 Analysis of Existing Regulatory Frameworks . . . . . . . . . . . . . . . . 12

7 Networking, Linkages and the NCM Transaction Scenarios. . . . . . . . . . . . . . . . . 17

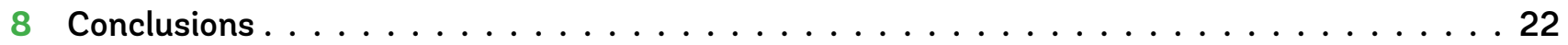

\section{Figures}

1 Hierarchy of Frameworks. . . . . . . . . . . . . . . . . 6

2 Direct Bilateral Linking . . . . . . . . . . . . . . . . . 18

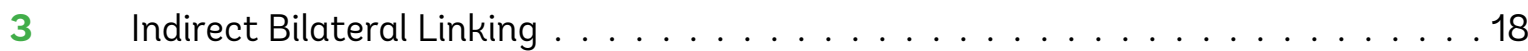

$4 \quad$ Networking . . . . . . . . . . . . . . . . . . . . 18

$5 \quad$ Carbon Club Model. . . . . . . . . . . . . . . . . . . . . . 18

6 Multilateral Trading Model . . . . . . . . . . . . . . . . . . . . 19

7 Possible Transaction Structures: Example of Country A Importing Units from Country B. . . . . . . . . . . . . . . . . . . . . 20 



\section{Executive Summary}

1.1. This paper considers the regulatory framework that is required to be put in place in order to support the establishment of carbon market linkages, in particular, in light of the bottom-up approach contemplated by the Paris Agreement. Section 2 describes the key purpose of the paper and details the assumptions and other factors that are made in this paper concerning 'networking'-a form of linking contemplated by the World Bank Group's Networked Carbon Markets (NCM) initiative. The key assumption in the paper is that the parties seeking to link two or more carbon markets will, before considering the regulatory elements required for linking, have concluded that there must be political, administrative and/or economic rationale for linking.

1.2. Section 3 considers the impact of the Paris Agreement, in particular Article 6, on carbon market linkage. With respect to Article 6, we assume that the scope and application of the transactions covered by this paper, in the context of networking, will be those which qualify as internationally transferred mitigation outcomes under the cooperative measures in Article 6(1-3).

1.3. Section 4 introduces the concepts of governance, legal and regulatory frameworks and seeks to draw a distinction between these three concepts, whilst recognising there is a degree of overlap. Whilst the required governance and legal frameworks are beyond the scope of this paper, both are a necessary precursor to a regulatory framework and so are considered briefly by way of context to our main discussion.

1.4. In section 5 we discuss the regulatory framework that we consider to be necessary for carbon market linking when considered in the context of traditional linkage models (i.e., those that require greater homogeneity in order to establish linkages). We conclude that the difference between the regulatory frameworks for bilateral and multilateral linkages is mostly one of scale and complexity. The additional regulatory bodies required by the bilateral model may be relatively few, whereas the multilateral model requires a more formal and tailored approach, often requiring a number of different regulatory bodies to be established. Whilst at a high level the structure of the regulatory framework in a generically linked market can be predicted based on existing models, the particular structure applied in the context of a linked carbon market would have to be tailored to the objectives of its legal framework and the specific issues that must be resolved to enable an effective linkage.

1.5. In section 6 we analyse a number of existing trading arrangements to assess whether they offer a suitable foundation for future linked carbon markets. This would potentially enable existing regulatory frameworks to be used as a means of jump-starting the linkage process. Ultimately for reasons on which we elaborate in the section, we conclude that most of them are not particularly suited to such purposes.

1.6. Section 7 includes a more detailed discussion of the World Bank Group's proposal for networking and the concept of mitigation value (MV) which is a fundamental element of networking. We consider the variety of modalities for linking, including the networking model and the NCM transaction scenarios discussed in the NCM Concept Paper (and summarised in Appendix 1). We go on to explore the regulatory framework considerations that are specific to these transactions and the MV concept. We conclude that using MV as a basis for linking creates a unique regulatory framework feature for linked countries that does not appear in the context of the traditional or classical linking model. This relates to the acceptance by one country of its MV assessment by a third party assessor. Although we highlight some of the new challenges this will throw up, we conclude that further development about how MV could be operationalised will be required before guidance on the regulatory framework for networking can be further advanced. 


\section{Introduction}

\subsection{Abstract}

2.1.1. The key purpose of this paper is to consider the regulatory framework that is required to be put in place to support the establishment of carbon market linkages, in particular, in light of the bottom-up approach contemplated by the Paris Agreement.

2.1.2. The successful conclusion of the Paris Agreement in December 2015 means that such consideration of linking under the World Bank's Networked Carbon Markets ("NCMM") initiative cannot be in the abstract and therefore, it is justified to consider the impact of Article 6 of the Paris Agreement in the context of this paper. Doing so also helps frame any discussion regarding linking of carbon markets. This statement reflects an assumption on our part that any country wishing to link with another would wish for its efforts through linking to either count towards its obligations under its nationally determined contributions ("NDC") under the Paris Agreement or, at the very least, not detract from its efforts under its NDC. The authors recognise that countries who engage in linkage efforts at a subnational level may not necessarily wish to ensure its efforts count towards its NDC (as that is a national prerogative), but would wish to avoid the risk of it having any prejudicial impact at a national level. Therefore, the scope of this paper also briefly considers the impact of Article 6 of the Paris Agreement on market linking.

\subsection{Assumptions}

2.2.1. As the transactional models highlighted in Appendix 1 of this paper illustrate, the concept of mitigation value ("MVV") is a fundamental element of the linking approach proposed by the NCM Initiative. However, how MV will be operationalised is, at the time of writing this paper, still very much under development. As such, it is necessary to assume that the nature of MV will be such that it justifies and supports linking between two or more carbon schemes or that the countries wishing to link will be suitably comfortable with the process of evaluating, publishing and applying MV. In the three transaction scenarios contemplated in Appendix 1, this assumption applies most to the domestic unit (the "International Transaction Unit" or "ITU") model.
2.2.2. Beyond $\mathrm{MV}$, in order for two or more countries or subnational level regions to link, there are a number of other factors or drivers that must be satisfied. Most fundamentally, there must be political, administrative and/or economic rationale for linking. The economic rationale for linking includes (but is not limited to) increasing cost efficiencies, greater heterogeneity of abatement costs, reducing competitive distortions and concerns surrounding leakage, increasing market liquidity, limiting the scope of market dominance of certain participants, etc. The administrative rationale for linking includes sharing best practices, lower cost of management, etc. The political rationale is often more tenuous; for example, the signalling of common efforts to combat climate change (Burtraw et al. (2013)). There are numerous papers which have discussed such rationales and the factors associated to that at length ${ }^{1}$ and we do not propose to repeat that discourse here. Needless to say, we must also assume that those factors would have been satisfied for the purposes of those countries or subnational level entities to link. It is only once they reach that point that considerations of the governance, legal and regulatory framework necessary to support such a linked arrangement begin to apply.

2.2.3. In no particular order, we therefore assume that the following factors, which are considered fundamental to any linkage arrangement (Tuerk et al. (2009)), have either been harmonised or the heterogeneities have been sufficiently accounted for in an MV that is applied:

i. the relative stringency of targets;

ii. eligibility of offsets credits;

iii. intensity targets; and

iv. cost containment measures.

2.2.4. In addition, we also assume that those factors that are not necessarily barriers to linkage but which nonetheless must be addressed as part of the linkage arrangement (Tuerk et al. (2009)), have been satisfied:

i. monitoring, reporting and verification ("MRVV") rules for units;

ii. banking compliance periods;

iii. compliance periods;

\footnotetext{
${ }^{1}$ See for example Tuerk et al. (2009), Burtraw et al. (2013), and Kachi et al. (2015).
} 
iv. registries;

v. rules governing new entrants and closures; and

vi. allocation methods.

2.2.5. It is, however, fair to say that much of the work referred to above and our assumptions have been in the context of more traditional approaches to linking (i.e., direct or indirect linking). Networking seeks to add a less traditional approach towards linking to respond to a new carbon market landscape that is decentralised and is characterised by heterogeneities in their design and ambition. We discuss this further in section 7 of this paper. 


\section{The Impact of the Paris Agreement on Linking}

3.1. Article 6 of the Paris Agreement contemplates three broad mechanisms: (I) cooperative approaches on a voluntary basis (Article 6(1)-(3)); (II) a mechanism to contribute to the mitigation of greenhouse gases and support sustainable development (Article 6(4)-(7)); and (III) a framework for nonmarket approaches (Article 6(8) and (9). For obvious reasons, the nonmarket approach is not relevant for networking (discussed in further detail at section 7 below). This leaves us to consider Article 6(1)(3) ("Cooperative Measures") and Article 6(4)-(7) (the "Sustainable Development Mechanism").

3.2. Cooperative Measures is a decentralised mechanism that allows voluntary bilateral and multilateral linkages of markets, for example, into a "carbon club." These linked markets may be able to trade internationally transferred mitigation outcomes ("ITMOs") in a manner supported by robust accounting to avoid double counting. It is clear that ITMOs are wider than the Kyoto Protocol concept of assigned amount units. We assume the generic nature of an ITMO is aimed at capturing multiple types of emission rights that may be the basis of the linkages established by two or more participating countries. Japan's current approach of signing bilateral offset agreements with certain countries may fit within this cooperative approach framework. Albeit stating the obvious, Cooperative Measures, like 'networking', has no relevance to domestic mitigation actions or their outcomes until such time as a decision is made for the ITMOs (that the action or outcome in question represents to be transferred internationally).

3.3. It is worth noting that there is nothing in the short description of an ITMO that would preclude the use of Cooperative Measures to apply to units/outcomes emanating from mechanisms or markets that are both within the authority of the COP (e.g., REDD+), as well as outside the authority of the COP (e.g., EUAs under the EU ETS via its link with Switzerland ${ }^{2}$ ). Furthermore, there is no qualitative requirement (e.g., additionality) in this mechanism which, conceptually, does not create a limitation on the type of ITMO available for international transfer.
3.4. It is important that the World Bank Group's proposal for networking align with Cooperative Measures in the requirement that Parties shall "apply robust accounting to ensure, inter alia, the avoidance of double counting, consistent with guidance adopted by the Conference of the Parties" (Article 6(2)). This means that, should a Party wish to 'network' as a means to link two or more carbon markets and wish for the international transfer of any ITMOs under that linkage to count towards the satisfaction of its obligations under its NDC, the networked markets would need to be consistent with any guidance or standards that the Conference of the Parties serving as the meeting of the Parties to the Paris Agreement ("CMA") develops pursuant to this article. We note that the CMA's guidance is not likely to be overly prescriptive and may be 'principles based', thereby allowing a lot of flexibility for interpretation at the national level of the Parties concerned. The less prescriptive the CMA's guidance, the more governments and market participants may need guidance from other sources. This is because, without sufficient guidance and oversight about accounting procedures, the less confidence governments and market participants will have about assets that are being traded. Without this confidence, there may be little trade of carbon assets. Ultimately, of course, the test will be whether the accounting approach adopted in the linked markets is consistent with the guidance on such accounting that is adopted by the CMA in its first session.

3.5. In contrast to the Cooperative Measures, the Sustainability Development Mechanism is a centralised mechanism with broad similarities to both the Kyoto Protocol's Clean Development Mechanism ("CDM") and Joint Implementation ("JI'). This mechanism allows for emission reductions achieved to be used by a Party to demonstrate achievement of its NDC. As such, with its additional mandate to support sustainable development, this mechanism will be broader in scope than the CDM and JI. It also does not differentiate between developed or developing countries as host Parties for the activity in question. Like the CDM and Jl, the new mechanism will

\footnotetext{
${ }^{2}$ We note that, in contrast to the approach of merely agreeing to cooperate in implementing the respective parties' NDCs envisaged by Article 6(1), should countries decide to aggregate their respective NDCs and meet those NDCs jointly (as may be the case for the EU member states), then such joint compliance is catered for by Article 4(16-18). Arguably, therefore, the EU ETS model of aggregating compliance under the Kyoto Protocol would fall within Article 4 while its measure of linking to Switzerland would, under the Paris Agreement, fall under Article 6(1).
} 
also allow for participation in the activity by private entities authorised by the relevant Parties.

3.6. On the face of it, the new mechanism seems to provide an opportunity to launch a centralised offset mechanism that benefits from all of the knowledge, knowhow and experience of CDM/JI. However, it also appears that this mechanism is not envisaged as a cap-and-trade mechanism and has the characteristics of an offset mechanism.

3.7. Given the centralised nature of the Sustainability Development Mechanism, it seems to preclude the application of networking because: (a) it is a 'top-down' mechanism that is operated by the CMA (and supervised by a body to be established by it); (b) it appears to be limited to offsets and would preclude cap-and-trade markets; and (c) does not, on its face, suggest an offset mechanism that would differentiate between various Party offsets on the basis of their MV.

3.8. As such, for the purposes of this paper, we will assume that the scope and application of the transactions to be covered by this paper in the context of networking will be limited to those, whose international transfers via their linked markets will qualify as ITMOs under Article 6(1)-(3) of the Paris Agreement. 


\section{Governance, Legal and Regulatory Frameworks}

\subsection{Distinguishing One from the Other}

4.1.1. In order to provide some shape to our discussion, it is worth reminding ourselves that governance, legal and regulatory frameworks are each distinguishable from one another and although there may be some crossover or overlap in the way they are created and applied, differences nonetheless do exist. Although there may be terms to define each of these concepts universally, to avoid any confusion, we nonetheless set out the definitions we propose to use for the purposes of this paper.

4.1.2. Governance "can be defined as the rule of the rulers, typically within a given set of rules. One might conclude that governance is the process-by which authority is conferred on rulers, by which they make the rules, and by which those rules are enforced and modified." ${ }^{\prime 3}$ As such, used in the context of networking and this paper, a governance framework would refer to the process by which a set of rules relating to the linkages between countries are established, how they are enforced and how any changes to those rules are brought about. Given the decentralized nature of the Cooperative Measures mechanism and the role of the CMA to provide guidance, it is not expected that the CMA will prescribe these rules and/or be the authority to enforce them. Therefore, the governance arrangements that prescribe the establishment and/or enforcement of linked carbon markets may be developed outside of the CMA.

4.1.3. A legal framework is a broad system of rules that governs and regulates decision making and is reflected in agreements, laws, etc. In the context of this paper, therefore, the legal framework would be the end product of the governance framework and it is the legal framework that specifies the boundaries within which the relationship of the linked countries are managed and regulated. By extension, if the legal framework is deficient in any respect (e.g., if there is no legal framework for private citizens of one country to seek remedies in the courts of another country in the context of a dispute in relation to ITMOs) then how that deficiency is addressed may fall within the realms of public international law rather than private international law (where the rights of private persons would normally otherwise be pursued).

4.1.4. Finally, a regulatory framework is defined as the existence of the necessary infrastructure to support the control, direction or implementation of a proposed or adopted course of action, rule, principle or law. Therefore, in the context of this paper, the regulatory framework refers to a group or set of bodies, agencies, actors and supervisors whose role is to oversee, implement and ensure the effectiveness of the linked markets in two or more countries. Again, given the decentralized nature of the Cooperative Measures mechanism (described in section 3), it is not expected that the CMA will provide this infrastructure and that the regulatory framework relating to the establishment and enforcement of linked carbon markets may be developed outside of the CMA.

4.1.5. It is important to recognise those differences in the context of this paper, in particular because discussion of the required governance and legal framework is beyond the scope of this paper. That said, the following points are worth making.

Figure 1: Hierarchy of Frameworks

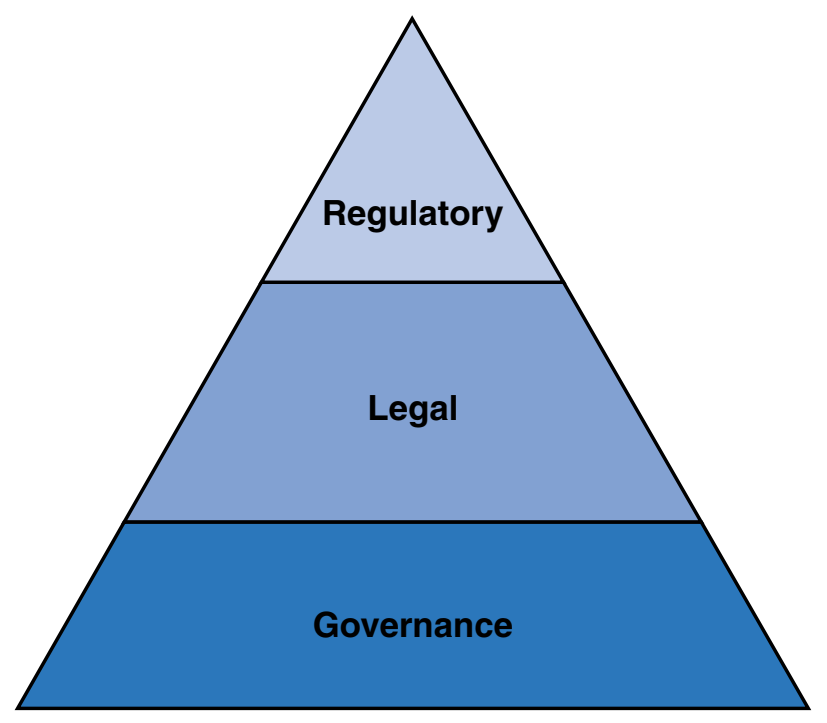

\footnotetext{
${ }^{3}$ From the World Bank website: http://web.worldbank.org/WBSITE/EXTERNAL/COUNTRIES/MENAEXT/EXTMNAREGTOPGOVERNANCE/ 0,,contentMDK:20513159 pagePK:34004173 piPK:34003707 theSitePK:497024,00.html
} 


\subsection{Governance Framework}

4.2.1. For linked markets, the multiplicity of issues that will need to be resolved (and which we have already assumed would have been agreed upon before the issue of the regulatory framework can be addressed) must nonetheless be addressed. The forum in which those issues are to be addressed and the process by which they are discussed goes to the heart of the governance framework. For example, in bilateral directly linked markets, that process may kick off through bilateral memoranda of understanding ("MOUs") or cooperation agreements between the parties. Examples of such arrangements include the recent US-China Climate Change Working Group under which they have launched action initiatives on vehicles, smart grids, carbon capture, utilization and storage, energy efficiency, greenhouse gas data management, forests and industrial boilers. From the seeds of such forums grow the more formal arrangements that lead to institutionalised governance structure. Ensuring such a forum exists to coordinate efforts is a key example of where a suitable governance structure can be important. It is also necessary to ensure there is a forum in which to address issues that cannot be resolved on a mutual basis. For example, if one party were to unilaterally wish to withdraw from a linked market and did so in contravention of the pre-agreed process under the legal framework that otherwise established that linkage, to which platform does the aggrieved country elevate that grievance (e.g., providing for resolution under the International Court of Justice or, in the context of a multilateral organisation, by developing an in-house dispute resolution forum for its members)?

\subsection{Legal Framework}

4.3.1. A distinction is also to be drawn between the legal frameworks required to support linkages at the national level from the subnational level. This is because, typically, international legal relations between two or more states are the subject of public international law and therefore, agreements made between two or more contracting states often take the form of international treaties. Although not always called a treaty, many terms are used to describe internationally binding relations between two or more countries. These terms include international conventions, international agreements, covenants, final acts, charters, MOUs, protocols, pacts, accords, and constitutions for international organisations. Usually, these different names have no legal significance in international law as the degree of formality chosen will typically depend upon the gravity of the problems dealt with and upon the political implications and intent of the parties. The EU's link with Switzerland is established through an agreement between the EU and Switzerland but until it is signed by the relevant authorities and ratified by the two parties, that agreement is not binding on the parties. In effect, this agreement is an international treaty within the meaning of the 1969 Vienna Convention on the Law of Treaties.

4.3.2. In contrast, linkages established at the subnational level by two or more countries will have to fit within limits imposed on those subnational agencies under the respective constitutional national laws of their respective nations dealing with international relations. For example, in order for a linkage between Quebec and California (discussed further below) to arise, the question of US national authority and sovereignty and whether the linkage interferes with the autonomy/policy choices of the national government, needed to be considered. Therefore, the shape of such linkages at the subnational level will be a question of the extent and scope of the subnational entity's jurisdiction. This can be a limiting factor in the ability for states or subnational entities to negotiate with each other in the context of market linkages. Where the efforts of two linked subnationals also need to ensure that, going forward, their efforts did not detract from the efforts at the national level counting towards their NDC under the Paris Agreement, this becomes a greater limiting factor for subnationals that are securing to link and will need to be taken into account in developing the legal framework.

4.3.3. Whatever legal framework that is applied in the context of two or more linked markets, whether that be through 'networking' or more classic forms of linking, that framework will lay the foundation for the regulatory framework to be established between two or more linked parties. It is not necessary for all of the details to be prescribed in the legal framework but it is important for authority to be delegated to the appropriate body or group of bodies in order for those details to be further developed. The absence in the legal framework of suitable organisations to delegate the responsibility of detailing policy development may lead to the creation of new organisations or bodies outside the scope of the legal framework in order to service the two linked markets. As such, the legal framework needs the foresight to anticipate potential issues that may have to be resolved between two or more countries or subnational entities. An illustration of such an issue faced by California during its considerations for linkage with Quebec included the following: "California might find a market design flaw that can only be corrected if Quebec implements the same market rule change. However, it would be 
difficult, if not impossible, for CARB to compel Quebec to implement this market rule." ${ }^{4}$ Arguably, the inability for one subnational to enforce a breach of a linking agreement against another country's subnational would be a significant design flaw for the linked markets. Other examples include the lack of harmonisation of EU VAT laws regarding EU allowances as part of the EU ETS establishment process in 2004. These laws were only harmonised recently following the VAT fraud scandal in the EU ETS in 2009/10.
4.3.4. The legal framework may also wish to address the exclusivity of the membership of the plurilateral or, to a lesser extent, the multilateral organisation. For example, will it be open for any country to join or would it be limited to its founding countries? Would it allow a country or international organisation to be an observer as a means to promote itself or its activities? 


\section{The Regulatory Framework for Carbon Markets Linked under the NCM}

\subsection{Regulatory Framework Issues in General}

5.1.1. The regulatory framework for a bilaterally linked market (whether direct or indirect), or a multilaterally linked market, will have to address the same issues. Where they differ is likely to be in terms of their size and complexity.

5.1.2. In this discussion of two or more linked carbon markets, it must be recognised that in each of the countries that are likely to be linked, there will probably already be in place a group or set of bodies, agencies, actors and supervisors whose role it is to oversee, implement and ensure the effectiveness of the carbon markets in their respective countries or subnational jurisdictions. It is important to note, therefore, that in the context of linkages of two or more such markets, the question is often not what the regulatory framework for a specific country is but rather what is the specific regulatory framework required to deal with linkage issues? Underpinning this question is the assumption that frameworks for linkages on bilateral and multilateral levels need to create sufficient homogeneity of the markets being linked, which in turn dictates the level of technical and political complexity.

\subsubsection{In some instances, especially in the directly} linked model, the institutions that are responsible for the regulation of the national or subnational market will also be the institutions given the role in the context of the linked markets. Perhaps, as in the case of the CaliforniaQuebec linkage, all that is done to address the issues arising from linkage is to add or create a new joint body. In this context, under the linkage agreement between California and Quebec, a Consultation Committee comprising one executive officer of each of the California Air Resources Board ("CARB") and the Quebec Ministry of Sustainable Development, Environment, Wildlife and Parks ("MoSDE") was established. Notably, there is no independent third party dispute resolution solution that the two parties here are willing to submit to in situations where the differences cannot ultimately be resolved.

5.1.4. Looking at the example of California-Quebec, it is worth noting that the other institutional arrangements that were required to be altered or added including:

- A consultative approach to address changes made to each of their respective programmes where those changes impact the harmonisation of the two markets. This also applies to changes to their respective offset protocols;

- The ability of each to void compliance instruments (i.e., allowances) that it has issued but not issued by the other;

- Notification to each other of any violations of rules by registered participants of each of their respective programmes;

- The creation of joint auction and common registry platforms;

- To coordinate on technical and administrative support for registered participants of the respective programs;

- To share information between themselves (to the extent permitted by their respective data privacy laws) to facilitate enforcement and avoid cases of fraud, abuse and market manipulation, etc.; and

- A mechanism to enable a party to withdraw on 12 months' notice. Notably, there is no mention of how to compensate any registered participant for any adverse financial consequences that may befall that party from its holding of carbon units of the withdrawing party or because of any other investment exposure it may have arising from an assumption that the linkage was enduring.

5.1.5. This list is not comprehensive but is illustrative of the issues that the legal framework would need to address to enable two directly linked markets to establish the regulatory framework to support it. As illustrated through this example, a single coordinating committee was deemed sufficient with much of the other necessary rule development, oversight and enforcement issues delegated to the bodies already existing under their own respective programmes or within the Western Climate Initiative ("WCI") arrangements.

5.1.6. However, this is slightly simplistic when 'networking' is factored into the equation because the question of who determines the respective MV of the two linked countries or subnationals has not yet been addressed. It is understood that the process would be independent and neutral, and that it would be designed to provide assurance of the environmental integrity of the asset, in accordance with rules and procedures that are recognized by regulations, the regulatory body and 
the participating jurisdictions. This step is not required for more traditional forms of linking. The key question for two markets that are 'networked', will relate to the regulatory framework that is used to apply the MV, as determined by a third party, for the respective schemes. We discuss this further in section 7 of this paper.

\subsection{The Regulatory Framework for Linked Markets}

5.2.1. As previously mentioned, the difference in the regulatory framework for bilateral and multilateral linkages are mostly one of scale and complexity. As illustrated by the California-Quebec example above, the additional regulatory bodies or institutions required in a bilateral model may be relatively few. However, this is not the case with plurilateral (i.e., regional or carbon clubs) or multilateral linked models. The complexity of those models, where the parties are signing up to a common set of rules, requires a more formal and structured approach to enable the formulation, development, elaboration, ratification, implementation and enforcement of those rules between the participating countries. This formalisation of approach often leads to the following types of bodies being established, each with a specific role to play to ensure the effective running of the carbon club or multilateral instrument:

5.2.2. A Decision Making Body: to make political decisions, carry out the functions of the body and take necessary actions. This is typically the apex level of the body made up of the most senior government representatives of the participating members of the carbon club countries or of the multilateral instrument. This body will typically meet once a year or with such other frequency as may be agreed or required.

5.2.3. An Administrative Body: to oversee the day-today running of the carbon club or multilateral instrument on behalf of the participating country representatives in the Decision Making Body. The Administrative Body will report to the Decision Making Body and is often supported by additional subsidiary committees or groups. The Administrative Body will also be made up of representatives of all the participating countries. This body will meet more regularly than the Decision Making Body, sometimes as frequently as every six weeks. Often this body will be empowered under the legal framework to determine its own rules of procedure as well as to establish any subsidiary bodies that it sees fit to support its activities. This body will often approve the rules of procedures of any committees or subsidiary bodies that it establishes. It may also formulate policy, review progress, identify new areas of cooperation and establish new mechanisms as required to implement the objectives of the club.

\subsubsection{A number of Sub-Administrative Bodies:}

may be required to deal with specific aspects of the plurilateral or multilateral arrangement. The rules of procedure of these bodies are often very thinly specified in the legal framework pursuant to which they were established and therefore, they are empowered to determine their own rules of procedure as they see fit. For example, a body may be set up specifically to deal with dispute resolution and enforcement issues relating to breaches by a country of its obligations under the rules of the instrument. Other examples of SubAdministrative Bodies may relate to those dealing with the fiscal or budgetary concerns of the instrument and the contributions of participating country members. After all, the operation of the various activities of the instrument, the resources necessary for organising the various meetings as well as costs of the permanent staff of the instrument's bodies and its secretariat will be a significant factor in the decision to establish the body in the first place. Under-resourced organisations are likely to be ineffectual in the implementation and performance of their objectives. This is particularly likely to be an issue where the club countries or multilateral instrument members require capacity-building support for the implementation of their obligations under the rules of the instrument.

\subsubsection{A number of technical committees and working groups: are required to achieve the often} mundane but nonetheless important nitty-gritty aspects of the instrument. The tasks of these committees or working groups may involve receiving notifications of new regulatory measures being proposed by its member countries, compiling databases of information (e.g., emissions data, monitoring reports, accounting information), conduct technical verification of documents, etc. The importance of these technical committees and working groups is sometimes understated. These platforms often provide the best source of ideas and information (to include discussion, elaboration, justification and contestation). Communication and cooperation between the participating countries in turn often have the effect of reducing the risk of conflicts arising between the parties concerned. These committees or working groups can also facilitate the development of shared norms between the participating countries, for example by providing a forum for airing views on the interpretation of specific or ambiguous provisions with the rules of procedure of the instrument or the legal framework under which the instrument was established. 
5.2.6. Often the technical committee or working group will be tasked with ensuring specific elements of the instrument. For example, in the case of traditional forms of linking, a working group may be tasked with ensuring the harmonisation of monitoring, reporting and verification arrangements across the participating countries. The task of harmonising is not as relevant for networking so a working group may be set up to develop the principles, rules and procedures for accepting an MV determined by a third party as well as how the suitable third party may be accredited as an MV assessor. Other examples include the running of specific tools of the instrument, such as an international transaction log to link up the carbon registries of the linked participating countries or, in the context of the International Transaction Unit model to operate the platform for issuing ITUs.

5.2.7. A Secretariat: The head of the secretariat may be appointed by the Decision Making Body. That person is likely to be empowered with the responsibility of appointing the staff to the secretariat, as well as setting their responsibilities, duties and terms of service, each of which may be under regulations adopted by the Decision Making Body. The Secretariat should be impartial towards any member country and should be exclusively international (as opposed to national) in character. Its role is to coordinate and monitor the decisions of the Decision Making Body and the activities of the organisations. It may also act as the point of communication with other international organisations or carbon clubs and its location will act as the headquarters for the carbon club or multilateral instrument.

5.2.8. In the table shown, we use the bodies under the South Asian Association of Regional Cooperation ("SAARC") (a plurilateral organisation) to illustrate how the bodies listed above have been established under that regulatory framework:

\begin{tabular}{|c|l|l|}
\hline Level & \multicolumn{1}{|c|}{ Body } & \multicolumn{1}{c|}{ SAARC Example } \\
\hline 1 & $\begin{array}{l}\text { Decision } \\
\text { Making Body }\end{array}$ & SAARC Heads of State Summit \\
\hline 2 & $\begin{array}{l}\text { Administrative } \\
\text { Body }\end{array}$ & Council of Ministers \\
\hline 3 & $\begin{array}{l}\text { Sub- } \\
\text { Administrative } \\
\text { Bodies }\end{array}$ & $\begin{array}{l}\text { Standing Committee/ } \\
\text { Programming Committee }\end{array}$ \\
\hline 4 & $\begin{array}{l}\text { Technical } \\
\text { Committees/ } \\
\text { Working } \\
\text { Groups }\end{array}$ & $\begin{array}{l}\text { Technical Committees- } \\
\text { (i) Agricultural, (ii) Transport and } \\
\text { Communications, (iii) Forestry, } \\
\text { Environment and Meteorology, } \\
\text { (iv) Social Development, } \\
\text { (v) Science and Technology, } \\
\text { (vi) Human Resource and } \\
\text { (vii) Energy. }\end{array}$ \\
\hline 5 & Secretariat & \begin{tabular}{l} 
SAARC Secretariat \\
\hline
\end{tabular} \\
\hline
\end{tabular}

5.2.9. Whilst any regulatory structure applied in the context of linked carbon markets would have to be tailored to the objectives of its legal framework and the specific issues that are needed to be resolved to create sufficient homogeneity and ensure the ability of those two or more participating markets to link, the bodies suggested above could, in principle, be applied to regulate most generically linked markets.

5.2.10. This of course raises the question of whether any current or existing plurilateral or multilateral arrangements could be used to link carbon markets using their existing legal or regulatory framework. We explore this in the following section. 


\section{Analysis of Existing Regulatory Frameworks}

\subsection{Introduction}

6.1.1. In this section, we review a number of existing regulatory frameworks that provide for trade on a bilateral, regional/plurilateral and multilateral basis and the challenges these existing frameworks might present for linked carbon market architecture. The historic challenge, particularly in the context of the bilateral linkages referred to below, has been to create a regulatory framework that achieves the required degree of homogeneity between the linked markets. The level of complexity in these regulatory frameworks is therefore largely driven by this assumed goal of homogeneity.

\subsection{Bilateral Linkage}

6.2.1. The EU-Swiss ETS linkage and California-Quebec linkage are two examples of recently established bilateral carbon market linkages, on a national and subnational level, respectively.

6.2.2. The EU-Swiss bilateral linkage represents the first such linkage by the EU. The technical negotiations were concluded in January 2016 and an agreement has been initialled, although not yet ratified as noted in paragraph 4.3.1 above. ${ }^{5}$ This will provide for mutual recognition of emission allowances between the two schemes. The precise details of the agreement are not covered in this paper as the agreement is not yet publicly available and little is otherwise known about its contents. The agreement will in essence be a form of international treaty once ratified.

\subsubsection{The California-Quebec linkage was formalised} in an agreement effective from 1 January $2014^{6}$ which was agreed under the auspices of the WCl: a regional collaboration to establish a combined carbon market intended to produce overall emissions reductions of $15 \%$ by 2020 . The agreement provides for a governance framework for collaboration on emissions reductions and trading, which, as noted in paragraph 5.1.3 above, includes:
- A consultation committee to monitor the coordination of the respective cap-and-trade programmes and report annually, comprised of one executive officer from each of the CARB and the MOSDE.

- A common registry for emissions allowances and offsets, and a common auction platform to enable joint auctions to be held.

- An obligation on the parties to work cooperatively to prevent fraud, abuse and market manipulation, and to ensure the reliability of joint auctions and their respective cap-and-trade programmes. ${ }^{7}$

6.2.4. In both of the cited examples of bilateral linkage, the arrangement could be more accurately described as an accession by one party to the established carbon market of the other. In the EU-Swiss linkage, many elements of the Swiss ETS were designed from the outset to match provisions in the EU ETS (e.g., allocation benchmarks) to facilitate subsequent linkage. The California-Quebec linkage was marginally less one sided. Nevertheless, it is still the case that Quebec redesigned elements of its cap-and-trade system so that it had equivalency with California's system in all key aspects. It is telling that, as a precondition to California implementing the linkage, the Californian governor had to make four key findings: (1) that Quebec's programme was similar or identical to California's in all material respects; (2) that linkage would not change California's ability to enforce its programme against entities located inside or outside California; (3) that Quebec's laws and regulations provided for equivalent enforcement of its cap-and-trade programme; and (4) that linking was unlikely to place any significant liability on California. ${ }^{8}$

6.2.5. The above illustrates that existing carbon market linkages on a bilateral level have required a high degree of harmonisation in relation to their respective emissions caps, price controls and other features of their systems, inevitably resulting in some loss of sovereignty and control over national carbon market policy. This loss of sovereignty and carbon market control is a common feature in direct

\footnotetext{
${ }^{5}$ As reported by Carbon Pulse in January 2016: http://carbon-pulse.com/14646/

${ }^{6}$ The agreement was between the California Air Resources Board and the Government du Quebec concerning the harmonisation and integration of cap-and-trade programs for reducing greenhouse gas emissions.

${ }^{7}$ Articles 8 to 12 of the California-Quebec Agreement.

${ }^{8}$ As noted in Carbon Market Watch paper, "Towards a Global Carbon Market, Risks of Linking the EU ETS to Other Carbon Markets" (2015).
} 
linkages, ${ }^{9}$ although the extent of the loss of sovereignty varies according to a variety of factors, as evidenced above. The loss of sovereignty issue is a major challenge to the adoption of direct linkages, particularly in the case of plurilateral or multilateral linkages.

6.2.6. Therefore, in order for direct linkages of the type established by the EU-Swiss and California-Quebec linkages to be viable, the following key aspects need to be addressed by the framework:

- How strictly the environmental integrity of a system is maintained, though MRV standards, i.e., so that there is sufficient alignment on the value of carbon allowances, meaning there is no mitigation value consideration.

- Whether the registry and accounting systems are aligned on issues such as carryover of allowances into future compliance periods.

- The level of ambition in the participant's domestic cap-and-trade system, i.e., at what level the regulatory emissions cap and reductions targets are set. This directly impacts on the price of carbon allowances.

- Whether a system has an absolute target or a relative target. The Chinese system-relatively-is unlikely to be compatible with the EU ETS for this reason.

6.2.7. It follows that there needs to be close alignment, not only a regulatory level, but also on a legal and governance level in order to achieve the necessary harmonisation in the direct linkage model. The requisite degree of alignment was self-evidently present in the case of the EU-Swiss linkage and the California-Quebec linkage, but the fact that examples of bilateral linkages are few in number (at least at present) suggests that the need to achieve this degree of multifaceted alignment is a potential limiting feature of the direct linkage model, particularly in terms of the ability to expand a bilateral linkage into an indirect bilateral linkage model (through multiple bilateral linkages, see Figure 3 on page 18) or the Multilateral Trading Model.

6.2.8. The EU ETS Directive ${ }^{10}$ contains strict requirements with regards to linking with other ETS schemes; it provides that such linkages may only be established if the other scheme is compatible and mandatory, and has absolute emissions caps. ${ }^{11}$ Even in the case of the EU-Swiss linkage, the negotiations took nearly 5 years to conclude an agreement. It therefore seems unlikely that the direct linkage model would work in the context of linking the EU ETS with more divergent, emerging carbon markets, given the regulatory, political and structural incompatibilities. As to the ability of the EU ETS to link under the MV model where direct linkage is not possible, it is unclear if this could happen as there is nothing in the directive to suggest that the strict compatibility requirements would not apply to such an agreement. This potential obstacle under the EU ETS may require further consideration.

6.2.9. Even if the required alignment can be achieved for the purposes of initial bilateral linkage, maintaining a harmonised, linked carbon market throughout the regulatory lifecycle of the respective systems may present a challenge. For example, Switzerland is targeting a 50\% reduction in its emissions (compared to 1990 levels) by 2030 , of which at least $30 \%$ must be achieved by Switzerland itself and the remaining 20\% achieved through the purchase of international offsets. ${ }^{12}$ Conversely, the use of offsets is excluded from the EU's 2030 target of achieving a $40 \%$ reduction. This policy divergence towards 2030 potentially represents a loss of control on the part of the EU, given the potential for international offsets to enter the combined market via the back door.

6.2.10. The California-Quebec agreement addresses the potential for regulatory divergence by providing for regulatory harmonisation measures, including a commitment to consult each other regularly and constructively to ensure ongoing harmonisation of the regulatory regimes for reporting of carbon emissions and cap-and-trade systems. ${ }^{13}$ This is one way to mitigate the risk of the parties having to de-link at some later stage due to regulatory incompatibility.

6.2.11. The need for close regulatory alignment in the direct linkage model could potentially be overcome through adoption of the Carbon Club Model or Multilateral Trading Model. However, it would not necessarily address origination concerns regarding, for example, the environmental integrity of units produced by another participant or their MRV standards. To address such concerns would require a higher degree of regulatory oversight by an appropriately qualified, independent decision making body, which the bilateral model presently does not provide for. The effort and cost of achieving this integrity assurance would suggest that networking would

\footnotetext{
${ }^{9}$ As noted by Ranson and Stavins in "Linkage of Greenhouse Gas Emissions Trading Systems: Learning from Experience" (2014).

${ }^{10}$ Directive 2003/87/EC establishing a scheme for greenhouse gas emission allowance trading within the Community and amending Council

Directive 96/61/EC.

${ }^{11}$ Article 25(1a).

${ }^{12}$ https://icapcarbonaction.com/en/about-emissions-trading/linking

${ }^{13}$ Articles 3 and 4 of the California-Quebec Agreement.
} 
be most cost effective on a plurilateral or multilateral basis, as common regulatory bodies could be utilised and the costs of supporting the regulatory infrastructure spread across more participants.

6.2.12. Geographic proximity also appears to be a significant feature in the majority of existing bilateral linkages. Whilst geographic proximity is not a necessary feature of bilateral linkage, the need for a high degree of regulatory and political alignment militates in favour of linking with geographically close partners. It follows from the discussion above that geographic proximity may be less of an issue with regards to linkage in the NCM model, but only if the requisite supervisory framework is in place.

\subsection{Regional/Plurilateral Linkage}

6.3.1. As noted above, the potential to develop a regional or plurilateral carbon club using the direct linkage model is inhibited by the requirement to have a high degree of regulatory, legal and governance alignment, and the loss of sovereignty that necessarily entails. Neither of the agreements cited in this section seek to interfere with the national sovereignty of its members on these issues, so their potential to support a direct linkage would appear to be low. However, linkage using the Carbon Club Model is not so inhibited, and so is considered.

6.3.2. The Agreement on South Asian Free Trade Area ("SAFTA") is a regional trade agreement that was established in 2004 by the members of SAARC. There is potential appeal in utilising a trade platform such as SAFTA to create a regional carbon club, in that it could provide an established regulatory framework and governance structure on which to build a specialised carbon trading platform. The institutional arrangements under SAFTA, consist of:

- SAFTA Ministerial Council ("SMC"): the highest decision making body of SAFTA, responsible for implementing the agreement.

- Committee of Experts ("COE"): provides expert support to the SMC in the implementation of the agreement, and acts as the Dispute Settlement Body under the agreement.

- SAARC Secretariat: provides secretarial support to the SMC and COE in the discharge of their functions under the agreement. ${ }^{14}$
6.3.3. The above bodies could potentially provide regulatory oversight of a linked carbon market within their existing powers. However, the SMC is likely to lack the requisite expertise in carbon market regulation, as compared to a body such as the CDM Executive Board; the narrow focus of SAFTA on trade in products is likely to mean that it is likely to be ill equipped to provide a sufficiently rigorous regulatory platform for trade in more complex instruments such as carbon allowances.

6.3.4. A further limiting feature of agreements like SAFTA is geographic exclusivity. Participation in SATFA is limited to SAARC states, which would limit the potential of its combined carbon market.

6.3.5. The Trans-Pacific Partnership ("TPP") Agreement is an example of a more recently established plurilateral trade agreement; again not one that seeks to establish a carbon market linkage. The agreement was signed by the 12 participating Pacific Rim countries in February 2016, although it has yet to be ratified. Whilst principally an agreement to establish a free trade area, the TPP (unlike SAFTA) also covers a wider range of issues over its 30 chapters, including intellectual property, labour and the environment.

6.3.6. The TPP does not expressly cover carbon markets and trading, nor does it impose a cap-and-trade scheme. However, Article 20(4) provides that the TPP members should enter into dialogue on trade and environmental issues of mutual interest, particularly with respect to the implementation of multilateral environmental agreements ("MEAs"). The Paris Agreement is likely to meet the definition of an MEA, so the implementation of Cooperative Measures and ITMOs (as discussed previously in paragraphs 3.2-3.4) is theoretically within the scope of the TPP. As such, there appears to be potential to utilise the framework established by the TPP to establish a linked carbon market.

6.3.7. A number of provisions in the environmental chapter are relevant to the question of whether the agreement could potentially provide a platform for carbon market linkage. Article 20(3) recognises the sovereign right of each party to establish its own levels of domestic environmental protection and its own environmental priorities. The retention of national sovereignty means that the TPP would not support a directly linked carbon club in which the parties cede control over domestic emissions reduction targets and carbon market control in favour of an EU ETS type system. However, it does potentially leave room for the MV model, in which participants would

\footnotetext{
${ }^{14}$ Article 10 of SAFTA.
} 
not necessarily need to relinquish sovereignty over their domestic carbon emissions policies.

6.3.8. Article 20 (12) promotes the use of cooperation frameworks as a mechanism to implement the environmental provisions of the TPP, which may be carried out on a bilateral or plurilateral basis. Whilst the establishment of a carbon market is perhaps outside the ambitions of the TPP, it is interesting that the language mirrors that of Article 6(1) of the Paris Agreement, which promotes voluntary cooperation to implement the parties' nationally determined contributions. Further, Article 20(15) makes reference to cooperation on emissions monitoring and market mechanisms.

6.3.9. An obvious limitation of utilising a framework such as the TPP as a platform for carbon market linkage is that it covers such an expansive range of topics, of which carbon markets if 'bolted on' would be only one small part. This means that countries wanting to join the carbon club established thereunder, who are not presently TPP participants, would potentially have to accede to the full agreement (there is no ability to unilaterally opt out of any provisions) and would have to be accepted for full TPP membership by the existing participants.

6.3.10. The TPP provides that accession is open to any country as may be agreed (unanimously) by the existing TPP members, provided that country is willing to comply with the obligations in the Agreement. ${ }^{15}$ Accordingly, unlike other free trade agreements such as SAFTA, there are no geographic limitations on membership, only a requirement that prospective members are willing to align with the TPP on all issues set out in the agreement. In this sense, it is not a regional agreement, with the connotations that has about exclusivity of membership; even amongst the existing TPP members (i.e., the Pacific Rim region), there is huge diversity in regulation, economic policy and governance, which demonstrates that alignment on such factors is not essential for membership.

6.3.11. The TPP may be a cumbersome instrument to utilise for a discrete issue such as carbon trading, albeit that it is still too early to make any judgments on this. The TPP provides for the establishment of a TPP Commission, whose functions will include monitoring and reviewing the implementation of the agreement. ${ }^{16}$ It is unlikely that the TPP Commission would have the requisite expertise or time to effectively supervise the establishment and functioning of a carbon club. However, the agreement

\footnotetext{
${ }^{15}$ Article $30(4)$ of the TPP.

${ }^{16}$ Article 27 of the TPP.

${ }^{17}$ https://www.wto.org/english/thewto_e/whatis_e/tif_e/org2_e.htm
}

gives wide discretion to the TPP Commission to establish subsidiary bodies and develop arrangements for implementing the agreement. Therefore, it would theoretically be within the powers of the TPP Commission to establish a subsidiary body dealing solely with the establishment of a networked carbon club, which would be accountable to the TPP Commission.

6.3.12. The above tends to suggest that the TPP could offer a regulatory platform for carbon market linkage on a plurilateral scale. Whether it would be a cost-efficient and operationally effective means to do so is questionable, and would require further detailed consideration.

\subsection{Multilateral Linkage}

6.4.1. The World Trade Organisation ("WTO") is an example of a global, multilateral trade framework. Various commentators have already considered whether the global carbon market and carbon units are caught by the WTO agreements-whether as a product, financial instrument or financial service-and the potential issues this creates. For the purposes of this paper, it is assumed that carbon units fall within the auspices of the WTO agreements and the analysis of its potential to support multilateral carbon market linkage is premised on that assumption.

6.4.2. The WTO operates under comprehensive institutional arrangements, which consist of the following bodies:

- General Council: the highest level decision making body, which also acts as the Dispute Settlement Body and the Trade Policy Review Body.

- Councils for Trade in Goods, Services and TradeRelated Aspects of Intellectual Property Rights: who have responsibility for the WTO Agreements, namely the General Agreement on Tariffs and Trade (GATT) and the General Agreement on Trade in Services (GATS); and

- Various committees and working groups: who deal with specific aspects of the WTO Agreements, and report to either the Councils for Trade and Services or directly to the General Council. ${ }^{17}$

6.4.3. The WTO certainly appears, on the face of it, to have sufficient prowess to provide the requisite regulatory oversight of a multilateral carbon market linkage. However, as noted in relation to the TPP, it may be cumbersome 
for a body such as the General Council to exercise a specialist regulatory function as a supervisory body of a global carbon market given its broad remit. Although the General Council could be supported in this function by the councils, committees and working parties below it, this may only serve to create an overly complicated governance structure.

6.4.4. One might argue that the United Nations Framework Convention on Climate Change ("UNFCCC") has an equally complicated governance structure. However, its climate change function is more focused and relevant than that of the WTO. Further, it is more likely that a body constituted under the UNFCCC, such as the CDM Executive Board, has the requisite specialist knowledge to act as an effective supervisor of a multilateral carbon market linkage. Therefore, there would need to be a compelling reason to elect the WTO framework over the UNFCCC as the primary platform for multilateral linkage.

6.4.5. That conclusion is reinforced when one considers the other regulatory obstacles presented by the WTO agreements. For example, the general prohibition on discrimination ${ }^{18}$ by obliging WTO members to afford most favoured nation treatment to all other members, could mean that discriminatory treatment of carbon units based on country of origin or type of unit (i.e., allowance or offset) violates WTO rules. Accordingly, prior commitments made by participants of the multilateral carbon club, for example through existing bilateral arrangements, may be classed as discriminatory. ${ }^{19}$ Equally, national measures imposing quantitative restrictions on the import of foreign carbon units could fall foul of the WTO rules against quantitative restrictions.

6.4.6. The applicability of these principles to carbon units-and the potential obstacles this may present for carbon market linkage under WTO-is by no means certain and would require further examination. Nonetheless, the potential complexity of bolting on carbon trading to the WTO framework militates in favour of adopting an alternative multilateral framework that does not start from such a position, such as UNFCCC.

\footnotetext{
${ }^{18}$ Article I of GATT.

${ }^{19}$ As posited by J. Munro in "Trade in Carbon Units as a Financial Service under International Trade Law: Recent Developments, Future Challenges" (2014).
} 


\section{Networking, Linkages and the NCM Transaction Scenarios}

\subsection{Networking}

7.1.1. This section considers 'networking' based on a number of concept discussion papers, but predominantly on the basis of the paper titled, 'Networked Carbon Markets-Key Elements of the Mitigation Value Assessment Process' (Macinante, October 2015) (the "NCM Concept Paper"). The transactions described in Appendix 1 are directly from the NCM Concept Paper.

7.1.2. In light of the bottom-up approach of the Paris Agreement, it is clear that national efforts will lead to many heterogeneous approaches to managing carbon pricing. As a result, the traditional approaches of direct and indirect linking that often require greater homogeneity ${ }^{20}$ before linkages can be successfully established, must be supplemented by other ways of considering linkages.

7.1.3. 'Networking' (also referred to as 'NCM systems') aims to enable the comparison of different carbon pricing systems and trade across different carbon assets with efficiency, transparency and integrity (Macinante, October 2015). The NCM initiative sees linking of diverse and heterogeneous carbon markets as desirable. Networking is about facilitating trade of carbon assets by recognising differences and placing a value on those differences through MV which allows systems to participate without necessarily aligning whilst still preserving the environmental integrity of trade. At the core of the networking concept is the need for a reliable analytical framework to better understand the differences between systems, in order to compare the relative "mitigation value" of carbon units and facilitate their trade. ${ }^{21}$

\subsection{Modalities for Linking}

7.2.1. As such, the variety of ways of linking may be illustrated as follows:

\begin{tabular}{|l|l|l|}
\hline $\begin{array}{c}\text { Modality } \\
\text { for } \\
\text { Linking }\end{array}$ & \multicolumn{1}{|c|}{$\begin{array}{c}\text { Scope for } \\
\text { Differences }\end{array}$} & \multicolumn{1}{c|}{ Description } \\
\hline Full Direct & $\begin{array}{l}\text { Requires greater } \\
\text { homogeneity }\end{array}$ & $\begin{array}{l}\text { Compliance unit in one } \\
\text { jurisdiction is accepted } \\
\text { without restriction in the } \\
\text { "linked" jurisdiction(s). }\end{array}$ \\
\hline $\begin{array}{l}\text { Limited } \\
\text { Direct }\end{array}$ & $\begin{array}{l}\text { Requires some } \\
\text { homogeneity }\end{array}$ & $\begin{array}{l}\text { Compliance unit } \\
\text { in one jurisdiction } \\
\text { is accepted with } \\
\text { qualitative/quantitative } \\
\text { restrictions in the "linked" } \\
\text { jurisdiction(s). }\end{array}$ \\
\hline Indirect & $\begin{array}{l}\text { Requires less } \\
\text { homogeneity }\end{array}$ & $\begin{array}{l}\text { Markets are not linked } \\
\text { directly, but have access } \\
\text { to a common third } \\
\text { carbon market. }\end{array}$ \\
\hline Networking & $\begin{array}{l}\text { Least } \\
\text { homogenous } \\
\text { and accomodates } \\
\text { greater } \\
\text { heterogeneity }\end{array}$ & $\begin{array}{l}\text { Fungibility of carbon } \\
\text { assets across schemes } \\
\text { facilitated by risk- } \\
\text { based assessment and } \\
\text { discounting. }\end{array}$ \\
\hline
\end{tabular}

7.2.2. The World Bank Group anticipates that a future international carbon market, whether through linking in the traditional sense or networking, would develop gradually and in a phased manner-starting with linked markets within countries, then bilaterally, on a regional/ multilateral basis and long term, helping markets link on a global basis.

\subsubsection{Bilateral and multilateral linkages effectively} create a common market for carbon units if there are no quantitative limits in or other restrictions in place. Carbon units originating in one or more markets are eligible for use in the others, and vice-versa. ${ }^{22}$ An example of such a Full Direct bilateral linkage is that between California and Quebec discussed above.

\footnotetext{
${ }^{20}$ Therefore, leading to greater delay in achieving the desired linkages.

${ }^{21}$ PMR and ICAP, "Emissions Trading in Practice: A Handbook on Design and Implementation" (2016, International Carbon Action Partnership \& the World Bank).

${ }^{22} \mathrm{lbid}$.
} 
Figure 2: Direct Bilateral Linking

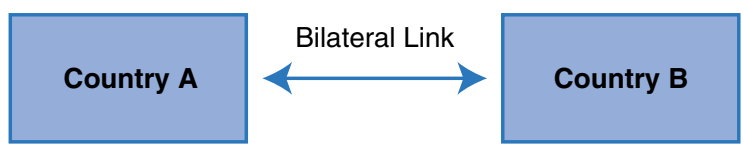

Figure 3: Indirect Bilateral Linking

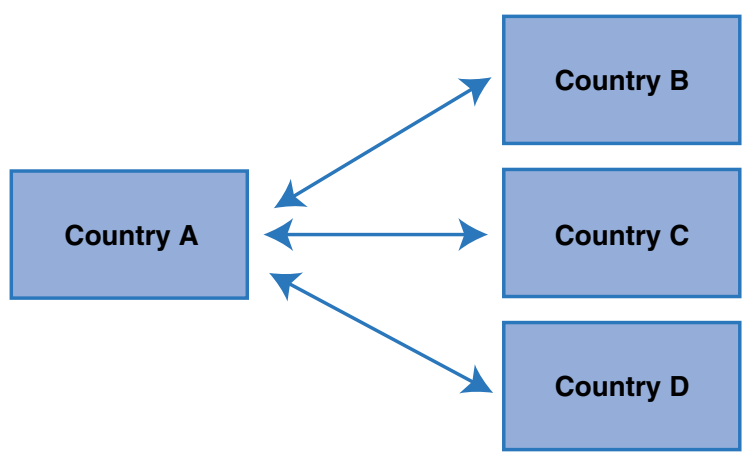

Countries $B, C$ and $D$ are each only indirectly linked via Country A.

\section{Figure 4: Networking}
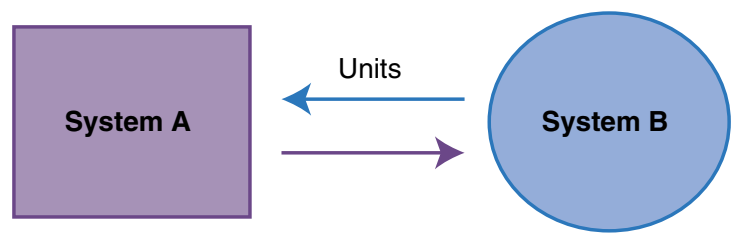

Source: NCM.

Note: Rather than linking schemes that are the same (e.g., linking two squares), networking seeks to link schemes that are different (e.g., linking squares and circles).

7.2.4. Unilateral linkages are also an example of direct linkages albeit one where emissions flow in one direction only, i.e., one system accepts units from one or more other systems, but not vice-versa. ${ }^{23}$

7.2.5. Indirect linkage occurs when two unlinked systems each link a common third system. ${ }^{24}$ Increasing in scale when numerous countries are linked, the participant countries (see for example the countries illustrated in Figure 3 as Country B, C, D, etc.) are indirectly linked via their common bilateral link with Country A.

7.2.6. If a global carbon price is the desired outcome, but with a recognition that the classical approaches of establishing homogeneity before linking is time consuming and challenging (as illustrated by the experiences described in the preceding sections of this paper) then finding alternative or softer linkage pathways, 'networking', is worth considering. Of course, networking requires the MV concept to be fully explored and accepted by participating jurisdictions which, while it may have political challenges, may be more practical and achievable, in the nearer term, than achieving agreement on a single homogeneous carbon market. At the heart of 'networking' is the idea that there should be an independent assessment framework to determine the climate change mitigation value of the different climate mitigation efforts to enable the carbon units from each scheme to be made fungible in another scheme or more broadly, in the international market.

\subsection{Scale of Linking}

7.3.1. Expanding on the points illustrated above, the linking of carbon markets can also be considered through the prism of its scale, for example, bilaterally (smaller scale) or multilaterally (larger scale). Within the multilateral context, there are at least two models that could be adopted that are differentiated in their scope by the number of participants and, therefore, scale.

7.3.2. The smaller multilateral model (see Figure 5 below) is where a number of countries within regional or geographic proximity or other political affiliations sign up to a set of common rules that they agree to apply in

Figure 5: Carbon Club Model

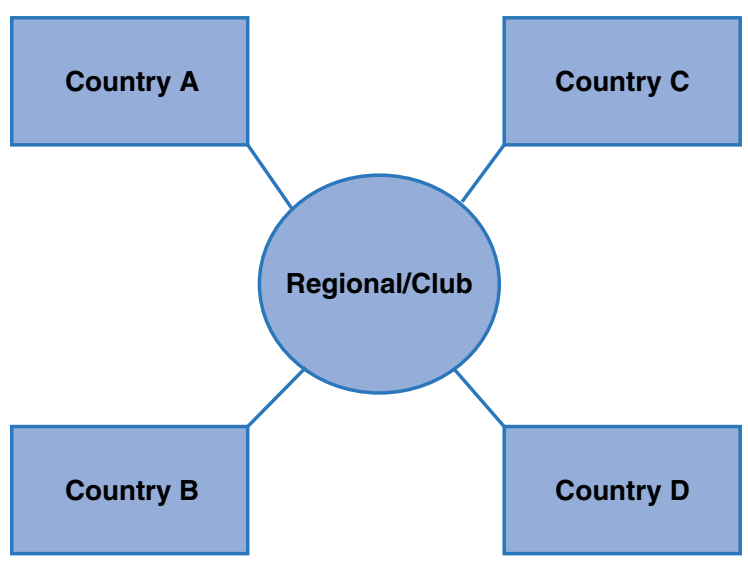


Figure 6: Multilateral Trading Model

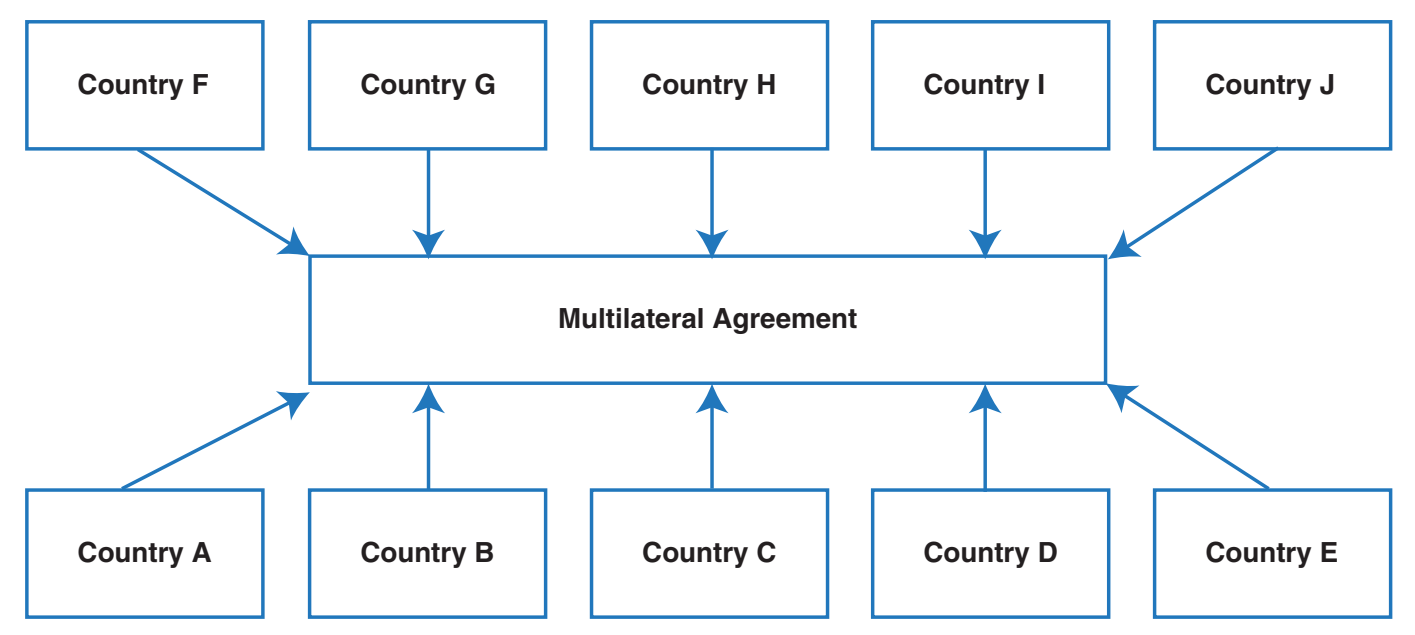

the context of their trading relationship with each other (the "Carbon Club Model"). This sort of club is often characterised as a 'carrot and stick' approach, where benefits are offered to attract countries to sign up to play by the rules and, therefore, exclude those who do not.

7.3.3. The larger multilateral model (see Figure 6 above) is where a lot of countries, with little or no geographic connectivity to each other, sign up to a common set of rules that they agree to apply in the context of their relationship, sometimes in the context of trading with each other but not exclusively so (the "Multilateral

Trading Model"). Examples of this model already exist such as the World Trade Organisation, the International Maritime Organisation and the International Civil Aviation Organization.

7.3.4. In the context of the multilateral linking approach described above, parallels may be drawn to the two notions of clubs described in the sister paper commissioned by the World Bank (Brewer, et al. 2016). That paper describes two notions of clubs; the first "emphasizes the role of benefits as incentives for participation and compliance... the [benefits] must be shareable among complying participants and excludable to non-participants and non-complying participants." In contrast, the second notion "has been stimulated and developed more inductively in an effort to supplement existing international institutional arrangements ... the key issue in this approach, then, is the size... in particular the number of governments involved in negotiations and therefore the prospective size of the institution or other arrangements." These two notions broadly reflect the two approaches to multilateral linkages described above.

\subsection{Transacting Carbon Assets in a Future International Market-the NCM Transactions (and their relevance in a regulatory framework)}

7.4.1. In order to provide a setting in which to assess the regulatory frameworks described in sections 5 and 6, this subsection considers the NCM transaction scenarios described in Appendix 1 (as extracted from the NCM Concept Paper).

7.4.2. Before seeking to address the regulatory framework for networking through $\mathrm{MV}$, it is first worth summarising the sample transactions highlighted in the NCM Concept Paper.

7.4.3. The NCM Concept Paper describes three possible options for networking transactional structures in a networked carbon market. For ease of reference, we have paraphrased Annex D of the NCM Concept Paper in Appendix 1 of this paper. However, those transactions make certain assumptions which necessitate a consideration of their impact on this paper.

7.4.4. We note that the NCM Concept Paper assumes that carbon units will be transferred via an intermediary (e.g., a settlement platform). Broadly speaking, these transactions, in the context of the linked markets, will involve (i) the import of a foreign unit from another country (the "foreign unit"); (ii) the conversion of a foreign unit into a local unit; and/or (iii) the issuance of a new unit by a third party entity following the surrender of the local unit to the third party and where the number of new issued units will be based on the applicable MV of that ITU. 
7.4.5. For the purposes of this paper and for ease of cross-reference against the NCM Concept Paper, we have adopted similar terms to describe the three transactional approaches set out in the NCM Concept Paper. These are, respectively:

i. the Foreign Unit Transaction model;

ii. the Foreign Unit Imported model; and

iii. the International Transaction Unit model (referred to as the 'Index Unit transaction currency model' in the NCM Concept Paper).

7.4.6. Please note that although this is not provided for in the NCM Concept Paper, in our assumptions above at sections 2 and 3, any of the units used in the transactions at (i) and (ii) above would appear to be treated as an ITMO under the Paris Agreement but it is less clear whether an ITU under the transactions falling within (iii) would qualify as an ITMO, given that the transfer may not be directly to another Party to the Paris Agreement but to a third party intermediary settlement platform (see p. 34 of the NCM Concept Paper). In order to qualify as an ITMO, it will be necessary to link the unit transferred to the third party intermediary and the subsequent ITU to a unit that is capable of being transferred to the acquiring party. Where that transfer is achieved in a third party intermediary platform, the mechanism leading to or achieving that transfer will arguably need to be recognised within the accounting guidelines to be developed by the CMA or else the acquisition by a party of the ITU for the purposes of its NDC will be frustrated.

\subsection{Regulatory Framework Issues Specific to $\mathrm{MV}$}

7.5.1. In each of the three transactional approaches described in the NCM Concept Paper, one country or subnational entity's unit is converted based on its MV. We note that the responsibility of determining the MV of a participating country or subnational is assumed to not be determined by that or another country or subnational as they would obviously risk certain biases. We agree with this assumption as it is difficult to foresee any country or subnational willing to have another country or subnational pass judgment on its relative MV where such assessment would result in any other outcome than $\mathrm{MV} \geq 1$.

7.5.2. As such, if some third party (without us passing comment on the identity or suitability of that third party) private sector entity, multilateral entity or international organisation were to be the assessor of the linked country or subnational's MV (the "MV Assessor"), the legal framework would also have to ensure that there was an acceptance between the two linked parties of the determinations made by the MV Assessor and establish a regulatory process to resolve issues arising from such determinations vis-a-vis the impact it would have on any conversion or mutual recognition of each other's units under the Foreign Unit Transaction model or the Foreign Unit Imported model. As mentioned in section 5, one option would be for participating jurisdictions/parties to establish a technical working group to agree on the principles, rules and procedures for accepting an MV

\section{Figure 7: Possible Transaction Structures: Example of Country A Importing Units from Country B}

\section{Foreign Unit Transaction Model}

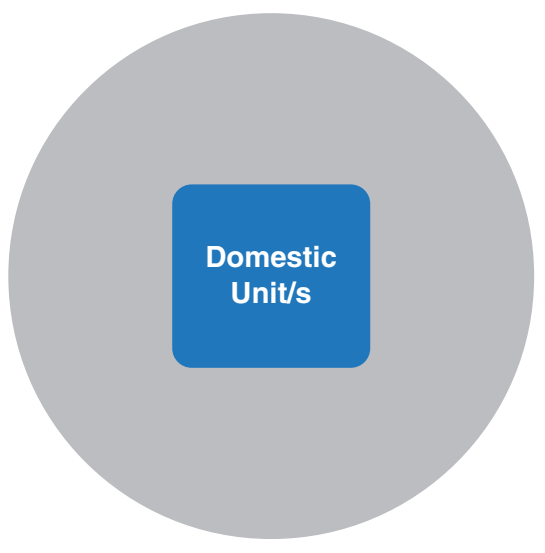

Imports are converted into a certain quantity of Country A units, based on the MV of Country B's units.
2. Foreign Unit Imported Model

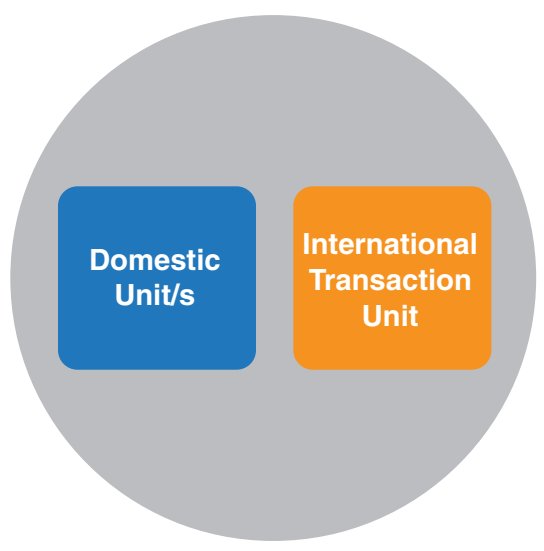

Imports are converted into a certain quantity of generic 'International Transaction Units', based on the MV of Country B's units.
3. Index Unit Model

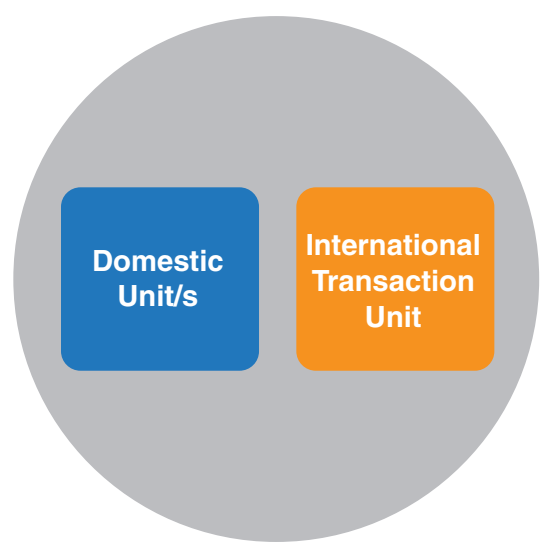

Imports are converted into a certain quantity of generic 'International Transaction Units' based on the MV of Country B's units, relative to an index. 
determined by the MV Assessor as well as how the third party may be accredited as the MV Assessor.

\subsubsection{The regulatory framework would also have to} consider the relationship between the compliance value and MV. We have assumed that the unit price would be set by market principles. Issues may arise, for example, where one of the linked parties seeks to add a qualitative criterion to the acceptance of the other party's unit that is in excess of any criteria used by the MV Assessor in setting the MV for the source country's unit. This becomes an even more acute issue in the context of the International Transaction Unit model because, in that, the ITU is not issued by either of the parties to the linked markets. The regulatory framework would have to reflect a solution to complaints raised by the other linked party regarding the inclusion of any additional qualitative criteria (unless that was agreed in advance as part of the legal framework negotiations). However, if the MV Assessor's mandate is, by necessity (in order to gain international acceptance (e.g., in a multilateral model)), limited in some of the factors it assesses as part of its process, it is possible to contemplate some countries wishing to add its own qualitative criteria on top of the MV. For example, Country B could say that it accepts that Country A's units are worth 5 ITUs via its MV but it could then say that if the ITU is sourced from an offset source that represents a methodology that Country B does not support, it will not accept those 5 ITUs. Whether such granular linkage between the ITU and Country A's units are going to be possible or necessary will only be determined once the MV calculation and ITU issuance process is further developed.

7.5.4. In the context of the concepts being considered as part of the NCM systems, other framework such as an 'international carbon asset reserve' (ICAR) or an 'international settlement platform', will create additional layers of regulatory consideration. In the case of an ICAR, the intention is to offer jurisdictions an alternative to establishing their own domestic carbon asset reserve, thereby lessening the resource requirement and additional regulatory considerations at the domestic level. The degree and complexity of these regulatory framework considerations will turn on whether the MV is used for the purposes of bilateral, multilateral or plurilateral linkages. For example, it is possible to envisage a single international settlement platform as well as a series of settlement platforms each representing a carbon club that uses MV as their basis for linking. A regulatory framework to address the above mentioned tools, will be on top of the regulatory framework aspects already identified in sections 5 and 6 of this paper.

7.5.5. In addition to those identified in paragraph 7.5.3 above, it is possible to envisage a multiplicity of matters that will require resolution under a regulatory framework that applies MV. To illustrate this point we set out some random examples of points that may need to be addressed depending on the linking modality and linking scale applied, in each case using MV:

- In the Foreign Unit Imported model, it would need to be agreed whether the conversion rate of a unit from Jurisdiction A to Jurisdiction B (based on the relationship of MV to compliance value) is static or dynamic. If the MV is based on a forecasted or anticipated basis, then when the forecast is revised (e.g., at an end of compliance phase), what impact does that have to the carbon units that were previously converted based on the earlier MV rate? There may be a range of options for how this is achieved but the regulatory framework must address this.

- In the Foreign Unit Transaction model, if the type of unit converted from Jurisdiction $A$ is an offset unit, but both Jurisdiction $A$ and Jurisdiction $B$ apply cap-andtrade mechanisms, how will the MV or Jurisdiction A impact offsets that arise outside Jurisdiction A's capand-trade mechanism? Will Jurisdiction A have both an MV for its offset programme and its cap-and-trade programme? What happens if Jurisdiction A expands the scope of its sectoral coverage, bringing the offset that was from a source originally outside the scope of that ETS, into it? The regulatory framework linking Jurisdiction A to Jurisdiction B will need to address the consequences of such events (e.g., it may need to have procedures to limit acceptance of units at the risk of double counting).

- In the International Transactional model, if a carbon club chose to establish a common single settlement platform for ITUs but retained their own national carbon registries for their own national units, how would a compliance obligation (e.g., a surrender of unit requirement) using ITUs as well as national units be practically managed without private sector participation in the international settlement platform? The regulatory framework for using an international settlement platform would need to address the issues associated with private (as opposed to state level) participation in an inter-governmental process, thereby potentially importing aspects of private international law in an otherwise pure public international law regulatory framework.

7.5.6. There are of course many other considerations arising from the MV assessment process, each party's acceptance of the MV Assessor's determination and the issuance of credits based on the MV for which solutions will have to be provided via the regulatory framework. However, it is not possible to articulate further regulatory aspects until the MV concept and process has matured further. 


\section{Conclusions}

8.1.1. The challenge of establishing a regulatory framework for carbon market linkages in the abstract is that it can only be done at a very high level. In the traditional model of linking whereby greater homogeneity is established, the specific considerations for a regulatory framework for linked carbon markets are likely to be influenced by the differences between the two markets that must be resolved prior to or as a condition of linking (in the bilateral linking model), or by the market design under the common set of rules to be established for the purposes of setting up the Carbon Club or multilateral instrument. The hierarchy of frameworks also means that the regulatory framework only follows from the legal framework, which itself follows from the governance framework.

\subsubsection{It is because of that challenge that this paper} does not seek to address questions of supervision and enforcement of linked markets. After all, as illustrated in the California-Quebec example, the question of how private citizens, participating in the scheme of one subnational are subjected to the enforcement jurisdiction of another subnational, was not addressed in its legal framework and therefore, there is no regulatory oversight other than presumably for each market or scheme to regulate its own actors and to invite one regulator to assist another on a cross border basis. Many other examples of regulatory supervision may arise because of the specific features or characteristics of the two markets to be linked.

\subsubsection{At a high level, the institutional regulatory} framework discussed in this paper will be familiar to many readers. This sort of institutional framework is common in many plurilateral or multilateral bodies and is not original or unique to the carbon markets. That said, one carbon market feature that does not arise in those models, and therefore is unique to carbon markets-is the registry and auction platform. However, whether (i) a common registry or auction platform is created for the linked markets, or (ii) the existing registries of the two markets are merely linked via a transactional log is a feature of the remaining differences of the two markets post linkage or of the overall market design for the linked markets. Certainly in the context of the Foreign Unit Transactional model and the Foreign Unit Imported model, a common registry or settlement platform in unlikely. However, in the International Transaction Unit model, an independent registry, on top of the respective registries for each of the linked parties would be contemplated.
8.1.4. We hope that it is clear from the paragraphs above, that it is difficult to suggest a regulatory framework for linked carbon markets without knowing the drivers for their linkage. We have provided a few examples to enable 'food for thought'. However, a lot more analysis will ultimately be required in respect of the governance and legal framework for the specific markets to be linked before additional granularity can be provided on the applicable regulatory structure. Using the MV as a basis for linkage creates the most significant regulatory framework feature between linked countries-that of acceptance of an MV assessed by the MV assessor. This is because this step is not required for more traditional forms of linking as there is usually an assumption, at the end of the negotiations that create the homogeneity required for traditional linking, that a tonne of $\mathrm{CO}_{2}$ is the same for each scheme. If this assumption were to not apply then, there would also be a need for acceptance between the two linked parties of the determinations made by the independent assessment process and establish a regulatory process to resolve any issues that arise from it. With this, all the questions that typically arise in relation to a third party assessment (e.g., withdrawal from the assessment, revision of the MV levels post facto, impact on investors, market certainty, fraud/corruption by the assessor, etc.) become material elements for the regulatory framework to consider.

8.1.5. In terms of our analysis of existing plurilateral and multilateral frameworks as suitable foundations for future linked carbon markets, we perceive most of them to not be particularly suitable for such purposes. One of the often raised criticisms of a platform that is primarily designed to promote trade is that those priorities will often conflict with environmental objectives. This can lead to a lack of effective integration and implementation of environmental policies as part of an organisation's work on trade. As such, few existing trade organisations include an environmental focus or chapter. Even if they do, they are given lower ranking priority to perceived greater goals. However, the TPP, as an example of a more modern trade agreement, seems to strike a better balance in recognising the importance of environmental policies as part of its broader remit. Therefore, the TPP may provide a better foundation for its members on which to build a linked carbon market than many of the other trade agreements where the environment or climate change is not its raison d'être. 


\section{Appendix 1}

\subsection{NCM Transaction Scenarios}

8.2.1. This part sets out three example NCM transaction scenarios:

- the Foreign Unit Converted model;

- the Foreign Unit Imported model; and

- the International Transaction Unit model.

Example NCM Transaction Scenario: Foreign Unit Converted Model

\begin{tabular}{|l|l|}
\hline \multicolumn{1}{|c|}{ Jurisdiction A } & \multicolumn{1}{c|}{ Jurisdiction B } \\
\hline MV = A & MV = B \\
\hline Trades A units & Trades B units \\
\hline $\begin{array}{l}\text { Compliance entity A wishes } \\
\text { to sell 12,000 A units to } \\
\text { Compliance entity B }\end{array}$ & $\begin{array}{l}\text { Compliance entity B wishes } \\
\text { to buy 12,000 A units from } \\
\text { Compliance entity A }\end{array}$ \\
\hline On xx/yy/zz date: & $\begin{array}{l}\text { e.g., MV A/B translates into an exchange rate of 1.5 } \\
\text { (that is, 1.5 A units = 1 B unit) }\end{array}$ \\
\hline $\begin{array}{l}\text { 12,000 A units debited } \\
\text { Compliance entity A's } \\
\text { account in A registry }\end{array}$ & $\begin{array}{l}\text { 8,000 B units credited } \\
\text { Compliance entity B's } \\
\text { account in B registry }\end{array}$ \\
\hline
\end{tabular}

\section{Transaction}

- The respective MVs of the two jurisdictions translate into an exchange rate between them (how this is worked out will be critical, but assume for the purpose of this example it can be).

- The counterparties agree how many of the seller's carbon units they wish to transact.

- The applicable exchange rate, on the date of the transaction, determines the number of carbon units that are credited to the buyer's account in the buyer's registry in the carbon units of the buyer's jurisdiction: the regulator/scheme administrator in Jurisdiction $B$ cancels the $12,000 \mathrm{~A}$ units received in the registry account and issues in their place $8,000 \mathrm{~B}$ units.

- The transacted number of seller's carbon units are debited from the seller's account in the seller's registry: regulator/scheme administrator in Jurisdiction $A$ does not need to do anything after the 12,000 A units have been transferred out of the A registry account.

\section{Compliance Value}

- Jurisdiction A regulator/scheme administrator determines the $\mathrm{CV}$ of $\mathrm{A}$ units.

- Jurisdiction B regulator/scheme administrator determines the $\mathrm{CV}$ of $\mathrm{B}$ units.

- CV does not come into the transaction equation, because the units surrendered against compliance in any jurisdiction will always only ever be the domestic units of that jurisdiction.

\section{Financial Value}

- The price reached by Seller A and Buyer B will be substantially influenced by the exchange rate on the date of the transaction, as in effect, this will determine the compliance value.

- As the exchange rate derives from the respective MVs, the price should be a reflection of the relative MVs of the two jurisdictions.

\section{Example NCM Transaction Scenario: Foreign Unit Imported Model}

\begin{tabular}{|l|l|}
\hline \multicolumn{1}{|c|}{ Jurisdiction A } & \multicolumn{1}{c|}{ Jurisdiction B } \\
\hline MV = A & MV = B \\
\hline Trades A units & Trades B units \\
\hline $\begin{array}{l}\text { Compliance entity A wishes } \\
\text { to sell 12,000 A units to } \\
\text { Compliance entity B }\end{array}$ & $\begin{array}{l}\text { Compliance entity B wishes } \\
\text { to buy 12,000 A units from } \\
\text { Compliance entity A }\end{array}$ \\
\hline On xx/yy/zz date: & \\
\hline $\begin{array}{l}\text { e.g., MV A/B translates into an exchange rate of 1.5 } \\
\text { (that is, 1.5 A units = 1 B unit) }\end{array}$ \\
\hline $\begin{array}{l}\text { 12,000 A units debited } \\
\text { Compliance entity A's } \\
\text { account in A registry }\end{array}$ & $\begin{array}{l}\text { 12,000 A units credited } \\
\text { Compliance entity B's } \\
\text { account in B registry }\end{array}$ \\
\hline
\end{tabular}

\section{Transaction}

- The respective MVs of the two jurisdictions translate into an exchange rate between them (how this is worked out will be critical, but assume for the purpose of this example it can be).

- The counterparties agree how many of the seller's carbon units they wish to transact. 
- The applicable exchange rate, on the date of the transaction, is immaterial to the transaction as the number of carbon units that are credited to the buyer's account in the buyer's registry are the same as the number debited from the seller's account in the seller's registry: the regulator/ scheme administrator in Jurisdiction $B$ by agreement with Jurisdiction $A$, accepts $A$ units and credits the $12000 \mathrm{~A}$ units received in the registry account to Compliance entity (buyer) B.

- The transacted number of seller's carbon units are debited from the seller's account in the seller's registry: regulator/scheme administrator in Jurisdiction A doesn't need to do anything after the 12,000 A units have been transferred out of the $A$ registry account.

\section{Compliance Value}

- Jurisdiction A regulator/scheme administrator determines the $\mathrm{CV}$ of $\mathrm{A}$ units.

- Jurisdiction B regulator/scheme administrator determines the $\mathrm{CV}$ of $\mathrm{B}$ units.

- CV becomes relevant on the date $[a a / b b / c c]$ that Compliance entity (buyer) B wishes to surrender them to the Jurisdiction B regulator/scheme administrator against compliance obligations under Jurisdiction B ETS. On that date, Jurisdiction B regulator/scheme administrator determines what CV to give to the Jurisdiction $A$ units. If the exchange rate has changed between the dates, $x \mathrm{x} / \mathrm{yy} / \mathrm{zz}$ and aa/bb/ $\mathrm{cc}$, then what the CV Buyer B gets for the $12,000 \mathrm{~A}$ units on aa/bb/cc may be different from that which would have applied on xx/yy/zz. Buyer B carries that risk.

\section{Financial Value}

- The price reached by Seller A and Buyer B will be influenced by the exchange rate on the date of the transaction, but only to the extent that: (a) the exchange rate is relevant to the $\mathrm{CV}$ on that date, which may be a function of the NCM arrangements, e.g., might be exchange rate on date of transfer converts directly to $\mathrm{CV}$, or alternatively, might be left up to Jurisdiction $B$ regulator/scheme administrator; and (b) the surrender date for compliance in Jurisdictional $\mathrm{B}$ is proximate to the transaction date.

Example NCM Transaction Scenario: International Transaction Unit Model

\begin{tabular}{|c|c|c|}
\hline Jurisdiction A & $\begin{array}{l}\text { Index ('Il') based on, e.g., all MVs } \\
\text { of trading jurisdictions; Index has } \\
\text { notional ITUs }\end{array}$ & Jurisdiction B \\
\hline $\mathrm{MV}=\mathrm{A}$ & & $\mathrm{MV}=\mathrm{B}$ \\
\hline Trades A units & & Trades B units \\
\hline $\begin{array}{l}\text { Compliance entity A wishes to sell } \\
12,000 \text { A units to Compliance entity B }\end{array}$ & & $\begin{array}{l}\text { Compliance entity B wishes to buy } \\
12,000 \text { A units from Compliance entity A }\end{array}$ \\
\hline \multicolumn{3}{|l|}{ On xx/yy/zz date: } \\
\hline \multicolumn{3}{|c|}{ e.g., MV A/II translates into an exchange rate of 0.67 (that is, $1.5 \mathrm{~A}$ units $=1$ ITU) } \\
\hline \multirow[t]{2}{*}{$\begin{array}{l}12,000 \text { A units debited Compliance } \\
\text { entity A's account in registry A }\end{array}$} & $\begin{array}{l}\text { 8,000 ITUs held in Seller A's pending } \\
\text { account on International Settlement } \\
\text { Platform }\end{array}$ & \\
\hline & $\begin{array}{l}\text { 8,000 ITUs transferred from Seller } \\
\text { A's pending account to Buyer B's } \\
\text { pending account }\end{array}$ & \\
\hline \multicolumn{3}{|c|}{ e.g., MV II/B translates into an exchange rate of 0.8 (that is, 0.8 ITUs $=1 \mathrm{~B}$ unit) } \\
\hline & & $\begin{array}{l}\text { 10,000 B units credited Compliance } \\
\text { entity B's account in registry B }\end{array}$ \\
\hline
\end{tabular}




\section{Transaction}

- The respective MVs of the two jurisdictions translate into an exchange rate between each of them respectively and the Index (how this is worked out will be critical, but assume for purpose of this example it can be).

- The counterparties agree how many of the Seller A's carbon units they wish to transact.

- The applicable exchange rate $\mathrm{A} / \mathrm{II}$, on the date of the transaction, determines the number of ITUs that are credited to the Seller A's pending account on the International Settlement Platform.

- On financial settlement, the ITUs in Seller A's pending account are transferred to Buyer B's pending account.

- The applicable exchange rate II/B, on the date of transaction (or on whichever date Buyer $B$ decides to move them from its International Settlement Platform pending account to its account in registry B), determines the number of $B$ units that are credited to the Buyer B's account in registry $B$.

\section{Compliance Value}

- Jurisdiction A regulator/scheme administrator determines the $\mathrm{CV}$ of $\mathrm{A}$ units.

- Jurisdiction B regulator/scheme administrator determines the $\mathrm{CV}$ of $\mathrm{B}$ units.
- CV does not come into the transaction equation, because the units surrendered against compliance in any jurisdiction will always only ever be the domestic units of that jurisdiction.

\section{Financial Value}

- The price reached by Seller A and Buyer B should be substantially influenced by the two exchange rates applicable on the date of the transaction, as in effect, this will determine the number of $B$ units received by $\mathrm{B}$.

- As the exchange rates derive from the respective MVs in relation to the Index, the price should be a reflection of the relative MVs of the two jurisdictions to the Index and ultimately, to each other.

- However, nothing above prevents the Buyer B from speculating on an improvement of the exchange rate II/B, by continuing to hold the ITUs in its pending account and only transferring them to its account in registry $B$ as $B$ units, when that more favourable rate applies or when it absolutely needs to, e.g., for compliance reasons. This would not impact in any way on the other elements, such as the $\mathrm{CV}$, since it would just be the number of $B$ units received in the $B$ registry that might vary. The ITUs held in this way in the pending account would only be able to be converted into B units. 



\section{References}

A. Petsonk and N. Keohane (August 2015) Creating a Club of Carbon Markets: Implications of the Trade System.

A. Tuerk, W. Sterk, E. Haites, M. Mehling, C. Flachsland, H. Kimura, R. Betz, and F. Jotzo (May 2009) Linking Emission Trading Schemes-synthesis report.

C. Hsueh (2013) A Greener Trade Agreement: Approaches to Environmental Issues in the TPP Negotiations.

Carbon Market Watch (May 2015) Towards a Global Carbon Market, Risks of Linking the EU ETS to Other Carbon Markets.

C. Kachi, N. Unger, K. Bohm, C. Stelmakh, M. Frerk Haug (2015) Linking Emissions Trading Systems: A Summary of Current Research.

D. Burtraw, K. Palmer, C. Munnings, P. Weber and M. Woerman (April 2013) Linking by DegreesIncremental Alignment of Cap-and-Trade Markets.

D. Meadows (February 2015) Procedures for EU ETS linking and an update on EU-Swiss linking negotiations.

E. Bailey, S. Borenstein, J. Bushnell, and F. Wolak (2012) Issue Analysis: Linkage with Quebec in California's Greenhouse Gas Emissions Cap-and-Trade Market (Emissions Market Assessment Committee for AB 32 Compliance Mechanisms).

International Carbon Action Partnership (January 2015) Linking Emissions Trading Systems: A Summary of Current Research.
J. Macinante (2015) Network Carbon Markets Key Elements Mitigation Value Assessment Process.

J. Meltzer (2014) The Trans-Pacific Partnership Agreement, the environment and climate change.

J. Munro (2014) Trade in Carbon Units as a Financial Service under International Trade Law: Recent Developments, Future Challenges.

M. Ranson and R. Stavins (July 2014) Linkage of Greenhouse Gas Emissions Trading Systems: Learning from Experience.

PMR and ICAP (2016, International Bank for Reconstruction and Development \& the World Bank) Emissions Trading in Practice: A Handbook on Design and Implementation.

R. Newell, W. Pizer and D. Raimi (2013) Carbon Markets 15 Years after Kyoto: Lessons Learned, New Challenges.

R. Vaiciulis and S. Fluker (December 2013) Linking the California and Quebec Emissions Trading Schemes.

T. Brewer, H. Derwent, and A. Blachowich (January 2016) Achieving Compatibility and Synergy between the Networked Carbon Markets Initiative and Climate Clubs.

UK Energy and Climate Change Committee (February 2015) Linking emissions trading systems, Fifth Report of the Session 2014-15.

W. Pizer and A. Yates (August 2014) Terminating Links between Emission Trading Programs, Discussion Paper. 
http://www.worldbank.org/en/topic/climatechange/brief/globally-networked-carbon-markets

Contact: Bianca Ingrid Sylvester

Tel: 202.473.4549

email: bsylvester@worldbank.org 